\title{
PAINFUL SCOLIOSIS AND OSTEOID OSTEOMA OF THE SPINE
}

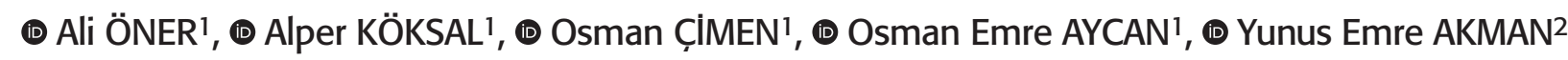 \\ ${ }^{1}$ Metin Sabancı Baltalimanı Osteopathic Training and Research Hospital, Clinic of Orthopedics and Traumatology, Istanbul, Turkey \\ ${ }^{2}$ istanbul Bilim University Faculty of Medicine, Department of Orthopedics and Traumatology, İstanbul, Turkey
}

\begin{abstract}
Objective: Osteoid osteoma $(\mathrm{OO})$ is a benign tumor seen mostly in the second decades of life. Posterior elements are usually affected, and atypical scoliosis can occur in these patients. Aim of this study is to evaluate the results of surgical treatment in 00 and to evaluate the fate of scoliosis. Materials and Methods: Between 2005 and 2018, online hospital database search was conducted for a diagnosis of 00 in the spine. Patient records were evaluated for recurrence and called for last follow-up.

Results: There were twelve patients (eight male, four female) operated due to spinal 00s, included in the study. Mean follow-up was 67.8 (13 to 139.7) months. Open surgery or radiofrequency ablation (RFA) were used for surgical treatment. Scoliosis was present in seven patients, and spontaneous correction was achieved postoperatively.

Conclusion: Atypical scoliosis may be the presenting symptom in juvenile and adolescents. Patients can be successfully treated by classic open surgery, and with RFA in last decade with a low recurrence rate. If the duration of symptoms is not prolonged and structural changes not occurred at diagnosis, spontaneous correction of scoliosis is achievable after treatment of spinal OOs.

Keywords: Osteoid osteoma, spine, atypical scoliosis, painful scoliosis
\end{abstract}

\section{INTRODUCTION}

Osteoid osteoma $(\mathrm{OO})$ is the most common benign spinal tumor in children. 00 comprises around $12 \%$ of benign bone tumors ${ }^{(1)}$. The etiology is unknown, and there is no report of malignant transformation. The presentation is in the first three decades of life, mostly in the second decade with male to female ratio of $2: 1^{(2,3)}$.

Tumor radius is less than $15 \mathrm{~mm}$, most often localized in cortical bone, while it can be in subperiosteal, intraarticular, or in cancellous bone. Due to the small size and the complex anatomy of the spine, it can be hard to see on plain radiographs. However, an isolated area of reactive cortical thickening from periosteal bone formation can be seen. Thin slice computerized tomography (CT) or bone scintigraphy should be used if there is a high suspicion of 00 clinically and the diagnosis with plain radiographs fails. In axial CT view, the nidus is seen as mineralized with a lucent halo and surrounded by a thick spherical or ovoid sclerosis. Bone scintigraphy shows increased activity. Magnetic resonance imaging (MRI) shows a large area of bone marrow and soft tissue edema, sometimes it can be confusing, which can lead to unnecessary further investigation for malignancy or infection ${ }^{(4)}$.
Ten to twenty percent of OOs occur in the spine, localized in the posterior elements of the spine (pedicles, superior and inferior articular processes, lamina, transverse, and spinous processes) in $93 \%$ of cases, and the remaining lesions in the corpus ${ }^{(5)}$. Elevated cyclooxygenase expression and subsequent increased synthesis of prostaglandin is thought to be the reason for pathogenesis of pain in $\mathrm{OOs}^{(6,7)}$. Localized pain in the spine is the most prominent symptom that worsens at night and coronal deformity may accompany ${ }^{(2,8)}$. Atypical scoliosis is thought to be the result of muscle spam secondary to inflammatory effect around the tumor, and the lesion is usually on the concave side of the curvature ${ }^{(8-10)}$. Pain relief responds well to acetylsalicylic acid (ASA) or non-steroidal anti-inflammatory drugs (NSAID).

Preferred treatment depends on the intensity of the pain, and the presence of coronal deformity in spinal OOs. Conservative treatment with anti-inflammatory drugs (ASA or NSAIDs) is generally not acceptable due to the severity of pain and morbidity of analgesics. Lately, radiofrequency ablation (RFA) is used in the treatment of $\mathrm{OOs}^{(11)}$. Average duration of symptoms until surgical treatment is around 17 months -2.6 years ${ }^{(8,10)}$. Even though painful scoliosis develops at presentation in majority of cases, the incidence is quite variable ${ }^{(5,8,10,12-14)}$. Coronal shift or scoliosis secondary to 00s may become persistent or be 
resolved in time, depending on the duration of symptoms and the age of the patient ${ }^{(8)}$.

The purpose of this retrospective study was to evaluate the clinical and radiological results of the treatment and to evaluate the fate of scoliosis in the patients with surgically treated $\mathrm{OO}$ of the spine at a single center.

\section{MATERIALS AND METHODS}

After obtaining ethical committee approval from Metin Sabancı Baltalimanı Osteopathic Training and Research Hospital Ethics Committee (date: 23.12.2019, decision no: 375), our tertiary hospital online database system was used to conduct a retrospective search. Patients with a diagnosis of OOs of the spine between 2005 and 2018 years were searched. Patients with insufficient data or patients with less than 12 months of follow-up were excluded.

Sixteen patients who were diagnosed as spinal OOs were found between the years of 2005 and 2018. Four patients were excluded from the study: two patients continued treatment at another center, another two patients had incomplete data and lost to follow-up. Therefore, twelve patients were included in the study. There were eight male and four female patients, with a mean age of 17.8 (7-34) years. The mean follow-up was 67.8 (13-139.7) months.

Radiographs, MRI and CT were used for radiological evaluation. Cobb angle and coronal shift measurements were performed on full spine PA and lateral radiographs. Physical examination, duration of symptoms till surgery, and neurological examination findings were recorded.

The patients were assessed according to the Enneking system for primary benign spine tumors ${ }^{(15)}$, in which all patients had stage 2 lesions. Stage 2 lesion was defined as combined osteolytic and osteosclerotic image, with well-defined borders. Weinstein-Boriani-Biagini (WBB) surgical staging system was also used for preoperative planning ${ }^{(16)}$. Axial spine image was divided into 12 sections, beginning from left side of spinous process, turning clockwise, and also A to $F$ defining soft tissue involvement.

OOs of the spine who could not comply with anti-inflammatory treatment or who had coronal deformity were all treated surgically until 2013. However, in selected cases of OOs, RFA has been the preferred method in our clinic, yet surgical excision has been used for RFA-inappropriate cases since 2013. Surgical excision with a posterior only approach was performed in nine patients and RFA was performed in four patients. The followup examinations were carried out in the $2^{\text {nd }}$ week, $6^{\text {th }}$ week, $3^{\text {rd }}$ month, $6^{\text {th }}$ month, and $1^{\text {st }}$ year, then annually if there was no sign of recurrence.

\section{Surgical Procedure}

All patients were operated under general anesthesia. The lesion site was marked under fluoroscopy guidance. After appropriate antisepsis preparations and posterior midline approach to spine, fluoroscopy was used to control the spine level again. If tumor was at the inner cortex or in pedicle, high speed burr was used to remove the outer cortex/Lamina to reach the 00. After the identification of the tumor tissue, aggressive curettage was performed. High speed burr was used to finish the borders of the tumor. If tumor location was suitable for en bloc resection, such as at the inferior or superior margin of lamina, osteotome or ultrasonic bone cutter (Misonix, Farmingdale, NY, USA) was used. If RFA was used, percutaneous kirschner wire or drill was used to approach the lesion under fluoroscopic guidance. The choice for the length of the probe, temperature and application time were determined according to the suggestions of RFA manufacturer.

\section{RESULTS}

Medical records of 12 patients were retrospectively reviewed, and the patients were called for last follow-up. Patient demographics, tumor locations, choice of treatment type, recurrence, preoperative and postoperative Cobb angles in scoliotic patients, follow-up and duration of symptoms were given in Table 1.

Scoliosis was present in seven patients preoperatively and was regressed at least $50 \%$ in six patients, and $40 \%$ regression was achieved in one patient.

There was recurrence in two lesions, both were treated primarily with RFA. In the first patient, the location of tumor was in the upper end plate, close to posterior cortex of the vertebral body of L4. Due to the difficulty in approaching the midline, posterior instrumentation was performed due to iatrogenic local instability after surgical resection. The lesion was placed in the right sacroiliac joint in the second patient. The pain was relieved for 6 months after RFA; however, due to progressive pain, a revision RFA was performed in the sacroiliac joint, and there was no recurrence in last follow-up for both patients.

Besides recurrences, there were no complications of surgical site infection and neurologic impairment.

\section{DISCUSSION}

Osteoid osteoma is a common benign primary bone tumor described by Bergstrand ${ }^{(17)}$ in 1935 and Jaffe ${ }^{(18)}$ described it as a distinct clinical entity. Nearly $3 \%$ of primary bone tumors are 00 , which has a male predominance, yet a variety of male to female ratio was described previously (male to female ratio: $3: 2$ to $3: 1)^{(5,12,14,19)}$, with an incidence of $10 \%$ to $25 \%$ in the spine ${ }^{(14)}$. Even though the predilection sites of OOs in the spine involve the posterior column, the vertebral body can also be the location. Patients with osteoid osteoma in the spine usually have spinal stiffness in addition to pain.

$\mathrm{X}$-ray examination has limitations in the diagnosis of OOs as the tumor is located in the posterior elements of the spine. Due to the complex anatomy of the spine, the diagnosis with X-ray alone was delayed historically. CT and MRI have been used more 


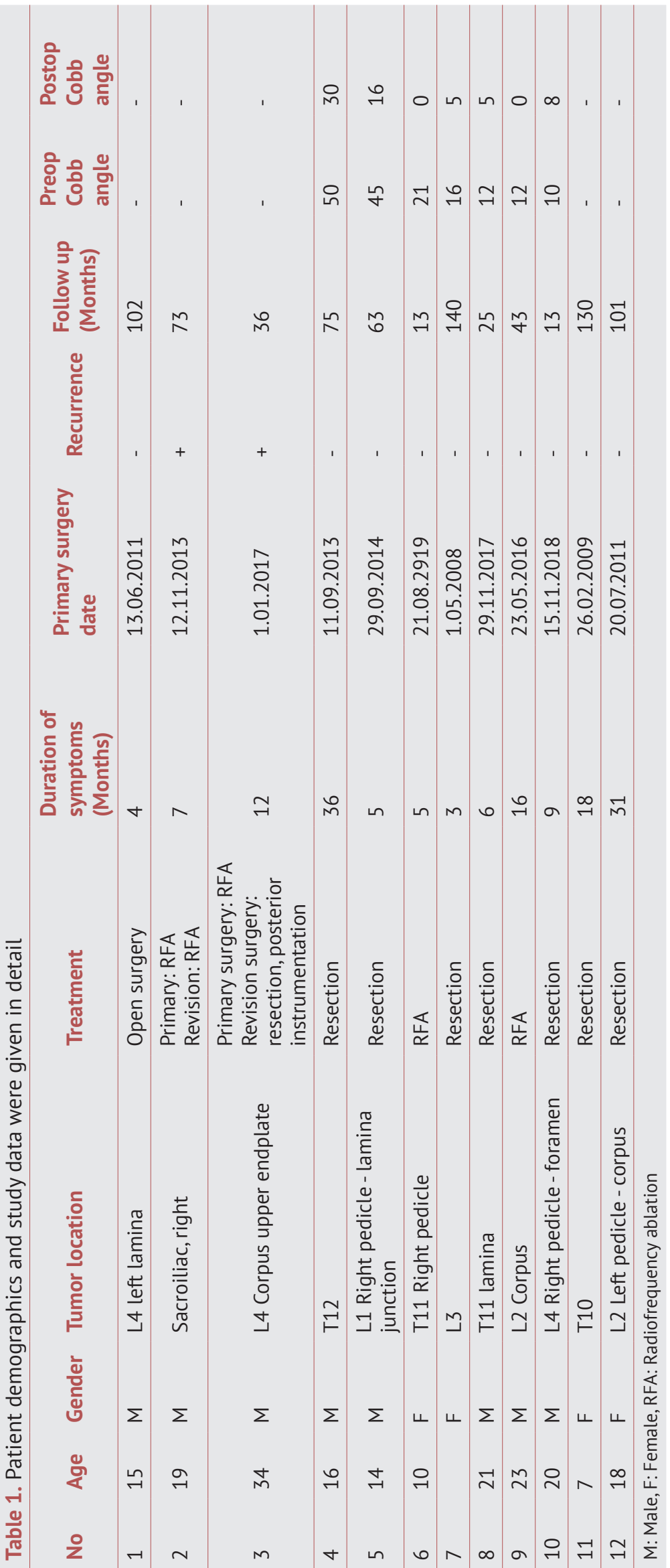

frequently to diagnose patients with back pain in the last two decades, yet it is still difficult to diagnose 00 in certain patients. Therefore, a bone scintigraphy should be obtained for diagnosis ${ }^{(5,20)}$ before CT and MRI studies, or in cases where diagnosis failed with already studied $\mathrm{CT}$ and/or MRI, yet high clinical suspicion of $\mathrm{OO}$ persists. Bone scintigraphy reveals the osteoblastic activity of $\mathrm{OO}$ as "hot spot" and it is helpful in localizing the tumor, it directs the CT examination to the pathology level ${ }^{(5)}$. The nidus is best seen by $\mathrm{CT}$ as a lytic nidus surrounded by a margin of dense sclerotic rim.

RFA has gained popularity in the last decade. A single session of RFA eliminates $80 \%$ of lesions. If there is failure or recurrence of symptoms, RFA can be applied again, and $96 \%$ are treated with a second session. Recurrence is mostly seen in 6 months ${ }^{(21)}$. In our clinical experience, RFA was first used in 2013. However, we used RFA in only four out of eight patients later. Preoperative evaluation of thin CT slices and the location of the lesion determine the choice of surgical excision or RFA. According to WBB surgical staging system, soft tissue involvement is described as A. Extraosseous soft tissues, B. Intraosseous (superficial), C. Intraosseous (deep), D. Extraosseous (extradural), E. Extraosseous (intradural), and F. Vertebral artery involvement. We have been using the WBB system, especially soft tissue involvement part, to answer the following questions to decide the treatment: 1 . Neurologically safe for RFA treatment? 2. Easy to reach with RFA? If answer is yes to both questions, RFA is preferred. In 2019, Yu et al.(22) reported the RFA indications as no neurological deficits, presence of intact cortical bone around lesions, and presence of cerebrospinal fluid (>1 $\mathrm{mm}$ ) between the lesion and the nerve root (or spinal cord) on MRI. Since 2013, we have been using the same protocol. If the location of the pathology is close to the neural structures, where neural tissue damage is the focus of concern due to the thermal injury of RFA, such as the subperiosteal region of spinal canal or neural foramen, or inner cortex of the lamina, superior or inferior articular processes (WBB D-E lesions), we prefer surgical excision. RFA is the preferred method in cases where the tumor is inside the pedicle, vertebral body, the subperiosteal region of outer cortex or the outer cortex (WBB A-C lesions).

Neurologic deficit rate is between $0 \%$ and $37 \%$ of patients with $0 \mathrm{Os}$ at presentation ${ }^{(5,10,12-14,23,24)}$. There were no cases with neurologic symptoms in our series. Neurologic symptoms appear in cases where tumor location is at the cortex or subperiosteal area of the inner cortex of posterior elements, or superior-inferior articular processes by the direct impingement of the tumor on neural tissue or by inflammation caused by the prostaglandins (PG) secreted from OOs (WBB staging $D-E)$. 
Aggravating nocturnal pain is the typical clinical manifestation. Even though nonsteroidal anti-inflammatory drugs (NSAIDs) or salicylates inhibit PG synthesis and are the first-line of treatment in extremity OOs, it is not always the case in spinal OOs. It takes about 33 months to resolve the symptoms with NSAIDs ${ }^{(25)}$. However, in patients with spinal deformity, the risk of structural transformation of the deformity becomes higher after 22 months $^{(8)}$, which canalizes the treatment to percutaneous or open surgical techniques. Yet, OOs of the spine without spinal deformity may be treated with NSAIDs, with careful monitoring for spinal deformity development and possible systemic complications for long-term use of NSAIDs. Patients in our series used NSAIDs for a short period. However, some of them complained that pain was not resolved to an acceptable level, and the rest of the patients who had less pain after NSAIDs objected using pain killer for a few years as a treatment of 00 . For patients at the early stages of 00, pain may not be the main presenting symptom ${ }^{(26)}$. Coronal imbalance may accompany patients without pain in the early stages. Therefore, atypical scoliosis may still alert the clinician for search of 00 in cases without pain.

The lumbar spine is the most commonly affected area, followed by the cervical, thoracic, and sacral regions. Distributions of anatomic location in our series were as one at the sacroiliac joint, seven in lumbar, four in thoracic spine, and none in the cervical region. Torticollis may accompany scoliosis or can be the sole symptom in cervical cases ${ }^{(5,24)}$. While there was no report of coronal imbalance in cases of sacral OOs, thoracolumbar spine OOs may present with coronal shift or scoliosis. The incidence of atypical scoliosis secondary to 00 varies from $20 \%$ to $70 \%$ and scoliosis is mainly due to muscle spasms and chronic inflammatory reactions surrounding the tumor. There were seven patients $(58.3 \%)$ with scoliosis in our series. Scoliosis was resolved spontaneously after RFA or open surgical excision in six patients (Figure 1), in whom the duration of symptoms

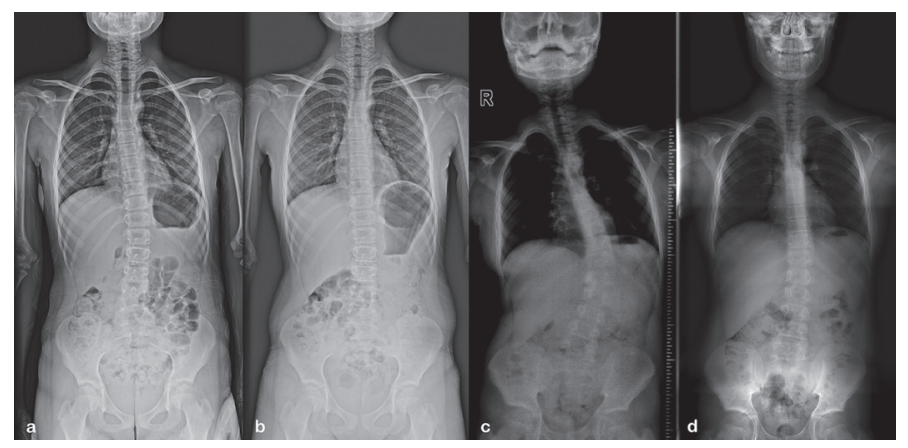

Figure 1. a. Female, 10 years old, lesion was at right pedicle of T11. Duration of symptoms was 5 months and RFA was preferred as treatment. b. Scoliosis regressed spontaneously after treatment from 21 degrees to normal in 13 months. c. Male, 14 years old, tumor was located at right pedicle-lamina junction. Cobb angle was 43 degrees preoperatively. Open surgery was performed. d. Scoliosis regressed to 12 degrees in 43 months

RFA: Radiofrequency ablation was between 3 and 16 months, yet only 40\% improvement was achieved in one case (from $50^{\circ}$ preoperatively to $30^{\circ}$ last follow-up) in which the duration of the symptoms was 36 months (Figure 2). Scoliosis seen in spinal OOs is usually postural and resolution of the curve is achieved by excision of the lesion. Since the most frequent presentation period of spinal OOs is the adolescence, an initial postural scoliosis may transform to structural scoliosis which has vertebral rotation(27) The duration of symptoms and the age at the presentation time are the most important factors in the development of associated vertebral rotation, a structural scoliosis with a high magnitude of curve ${ }^{(8,27)}$. The expected ratio of spontaneous correction of scoliosis is lower when the duration of symptoms is longer.

\section{Study Limitations}

The limitations of the present study are the retrospective design, heterogeneity of the patients' group and the small sample size. Also, there is no information about the superiority of one treatment over the other, and upper limit for duration of symptoms is still in debate about spontaneous scoliosis correction. Therefore, multi-center prospective studies are necessary to evaluate these questions.

\section{CONCLUSION}

The upper limit for duration of symptoms to achieve spontaneous scoliosis correction depends on the location of the tumor, presence of neural symptoms, and skeletal maturity. After surgical excision or RFA treatment of scoliosis, total spontaneous correction of deformity is expected in patients without structural changes, and in patients with structural changes, scoliosis deformity can regress to some degree.

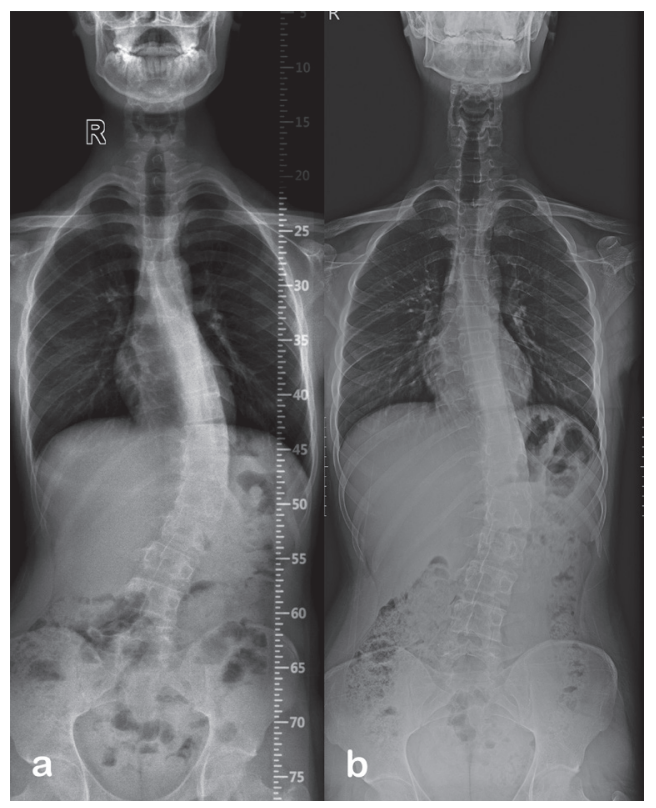

Figure 2. a. Male, 16 years old, tumor was located at T12, and duration of symptoms was 36 months. Open surgery was performed. b. Scoliosis regressed to 30 degrees 


\section{Ethics}

Ethics Committee Approval: Ethical committee approval was obtained from Metin Sabancı Baltalimanı Osteopathic Training and Research Hospital Ethics Committee (date: 23.12.2019, decision no: 375).

Informed Consent: Retrospective study.

\section{Authorship Contributions}

Surgical and Medical Practices: A.Ö., A.K., O.Ç., O.E.A., Y.E.A., Concept: A.Ö., Y.E.A., Design: A.Ö., Data Collection or Processing: O.Ç., O.E.A., A.K., Analysis or Interpretation: O.Ç., O.E.A., Literature Search: A.K., O.Ç., O.E.A., Writing: A.Ö., Y.E.A.

Conflict of Interest: No conflict of interest was declared by the authors.

Financial Disclosure: The authors declared that this study received no financial support.

\section{REFERENCES}

1. Greenspan A. Benign bone-forming lesions: osteoma, osteoid osteoma, and osteoblastoma. Clinical, imaging, pathologic, and differential considerations. Skeletal Radiology. 1993;22:485-500.

2. Jackson RP, Reckling FW, Mantz FA. Osteoid osteoma and osteoblastoma. Similar histologic lesions with different natural histories. Clin Orthop Relat Res. 1977:303-13.

3. Healey JH, Ghelman B. Osteoid Osteoma and Osteoblastoma Current Concepts and Recent Advances. Clin Orthop Relat Res. 1986:76-85.

4. Davies M, Cassar-Pullicino VN, Davies AM, McCall IW, Tyrrell PN. The diagnostic accuracy of MR imaging in osteoid osteoma. Skeletal Radiol. 2002:559-69.

5. Azouz EM, Kozlowski K, Marton D, Sprague P, Zerhouni A, Asselah F. Osteoid osteoma and osteoblastoma of the spine in children. Report of 22 cases with brief literature review. Pediatric Radiology. 1986;16:25-31.

6. Greco F, Tamburrelli F, Ciabattoni G. Prostaglandins in osteoid osteoma. Int Orthop. 1991;15:35-37.

7. Mungo DV, Zhang X, O'Keefe RJ, Rosier RN, Puzas JE, Schwarz EM. COX-1 and COX-2 expression in osteoid osteomas. J Orthop Res. 2002;20:159-62.

8. Balioglu MB, Albayrak A, Atici Y, Sökücü S, Tacal MT, Kaygusuz MA. The effect of simple local resection on pain and scoliotic curve in patients with scoliosis secondary to osteoid osteoma and osteoblastoma in the spine. Acta Orthop Traumatol Turc. 2016;50:330-8.

9. Kan P, Schmidt MH. Osteoid Osteoma and Osteoblastoma of the Spine. Neurosurgery Clinics of North America 2008;19:65-70.

10. Ozaki T, Liljenqvist U, Hillmann A, Halm H, Lindner N, Gosheger G, et al. Osteoid osteoma and osteoblastoma of the spine: experiences with 22 patients. Clin Orthop Relat Res. 2002:394-402.
11. Wang B, Han SB, Jiang L, Yuan HS, Liu C, Zhu B, et al. Percutaneous radiofrequency ablation for spinal osteoid osteoma and osteoblastoma. Eur Spine J. 2017:1884-92.

12. Pettine KA, Klassen RA. Osteoid-osteoma and osteoblastoma of the spine. J Bone Joint Surg Am. 1986;68:354-61.

13. Raskas DS, Graziano GP, Herzenberg JE, Heidelberger KP, Hensinger RN. Osteoid osteoma and osteoblastoma of the spine. J Spinal Disord. 1992;5:204-11.

14. Zileli M, Cagli S, Basdemir G, Ersahin Y. Osteoid osteomas and osteoblastomas of the spine. Neurosurg Focus. 2003;15:1-7.

15. Enneking WF. A system of staging musculoskeletal neoplasms. Clin Orthop Relat Res. 1986:9-24.

16. Boriani S, Weinstein JN, Biagini R. Primary bone tumors of the spine. Terminology and surgical staging. Spine (Phila Pa 1976). 1997;22:1036-44.

17. Bergstrand H. Uuber Eine Eigenartige, Wahrscheinlich Bisher Nicht Beschriebene Osteoblastische Krankheit in Den Langen Knochen Der Hand Und Des Fusses. Acta radiol. 1930;11:596-613.

18. Jaffe HL. Osteoid osteoma: a benign osteoblastic tumor composed of osteoid and atypical bone. Arch Surg. 1935;31:709-28.

19. Esteban Cuesta H, Martel Villagran J, Bueno Horcajadas A, Kassarjian A, Rodriguez Caravaca G. Percutaneous radiofrequency ablation in osteoid osteoma: Tips and tricks in special scenarios. Eur J Radiol. 2018;102:169-75.

20. Mandell GA, Harcke HT. Scintigraphy of spinal disorders in adolescents. Skeletal Radiology. 1993;22:393-401.

21. Vanderschueren GM, Obermann WR, Dijkstra SP, Taminiau AH, Bloem JL, Van Erkel AR. Radiofrequency ablation of spinal osteoid osteoma: clinical outcome. Spine (Phila Pa 1976). 2009;34:901-4.

22. Yu X, Wang B, Yang S, Han S, Jiang L, Liu X, et al. Percutaneous radiofrequency ablation versus open surgical resection for spinal osteoid osteoma. Spine J. 2019;19:509-15.

23. Wang GQ, Kang YJ, Lv GH, Li YW, Wang B. Osteoid osteoma leading to sciatica. Spine J. 2016;16:e315.

24. Etemadifar MR, Hadi A. Clinical Findings and Results of Surgical Resection in 19 Cases of Spinal Osteoid Osteoma. Asian Spine J. 2015;9:386-93.

25. Kneisl JS, Simon MA. Medical management compared with operative treatment for osteoid-osteoma. J Bone Joint Surg Am. 1992; 74:179-85.

26. Aydinli U, Ozturk C, Ersozlu S, Filiz G. Results of surgical treatment of osteoid osteoma of the spine. Acta Orthop Belg. 2003;69:350-4.

27. Ransford A, Pozo JL, Hutton PA, Kirwan EO. The behaviour pattern of the scoliosis associated with osteoid osteoma or osteoblastoma of the spine. J Bone Joint Surg Br. 1984;66:16-20. 